\title{
Measuring the Impact of Infrastructure Quality on Firm Performance: a Review of Literature, Metrics, and Evidence
}

\author{
Ha Thi Thu TRANG ${ }^{*}$, Pham Thi Thanh HONG ${ }^{2}$ \\ 1,2 Department of Business Administration, School of Economics and Management, Hanoi University of Science and \\ Technology, Hanoi, Vietnam \\ *Corresponding author: trang.hathithu@hust.edu.vn
}

\begin{abstract}
Research purpose:

This paper aims to provide a selective overview of recent studies on measuring the impact of infrastructure quality on firm performance. In particular, the paper identifies relevant definitions and metrics that are widely used for research, reviewing the key findings to date for infrastructure impact analysis with a focus on studies addressing developing countries. Then, the range of computer analytical methods and tools used to estimate impact is meticulously examined in accordance with the availability of various types of data.

Research motivation:

Infrastructure quality is an important part of the production process. Limited public service quality may directly or indirectly affect the economic activities of firms. However, measuring the impact of infrastructure quality on business activities is highly dependent on the availability of data types. Therefore, in the research of infrastructure impact analysis, it is necessary to determine relevant indicators and estimation techniques for each type of available data.

Research design, approach and method:

Systematic review is applied to provide a summary of recent studies and to answer the research question. We searched for literature on the impact of infrastructure on firms from 2005 to 2021. Then, from the selected research reports, we checked the data set used in the literature, and selected the research based on firm-level database.

Main findings:

The paper finds that infrastructure quality measured by length of road/highway, duration of electricity/water suspension, length of internet cables are the relevant metrics in the studies of infrastructure impact analysis. In addition, capacity utilization rate and total factor productivity (TFP) are widely used as indicators for firm performance. The paper indicates the key influences of various infrastructure sectors on business activities which can be summarized as: (1) High-quality infrastructure services play a vital role for both firm's growth and its competitiveness; (2) Quality of road infrastructure is important to explain patterns of absolute advantage, explaining why firm in one region produce more efficiently than firm in others; (3) Quality of power supply and telecommunication infrastructure is important for explaining patterns of comparative advantage which introduces opportunity cost as a factor for analysis in choosing between different options for production diversification.
\end{abstract}

Practical/managerial implications:

The paper provides a guideline to conduct an infrastructure impact analysis based on firm-level data.

Keywords: literature review, public infrastructure, infrastructure metrics, firm performance, firm productivity, capacity utilization, impact analysis, firm-level data

\section{BACKGROUND AND MOTIVATION}

Infrastructure is one of the key components of production and economic development. The definition of infrastructure can be explained as the totality of fundamental physical facilities upon which all other ranging from economic, social, and political activities. Infrastructure are those services without which primary, secondary, and tertiary production cannot work and that will lead to negative business performance. Infrastructure includes utilities such as roads, railways, port facilities, electricity, water supply and telecommunications networks. Fluctuations in the quality of infrastructure used in the production processes will significantly affect the performance of firms in terms of quantity of output, income, profits, and productivity. At macro level, it can lead to a job creation in the regional economy since a reliable infrastructure system promotes agglomeration of economic activities. Quality infrastructure is also viral for foreign direct investment and consequently boost international trade.

Even though the presence and quality of infrastructure directly affecting economic development, the availability of proper infrastructure in most developing countries is still limited. Lack of proper infrastructure in developing countries has affected the abilities of their firms to fairly compete in the global market. Unreliable infrastructure systems affect firms through various impact channels, which can be categorized by: (i) direct impact, (ii) indirect impact, and (iii) induced impact. 
(i) Direct impact: Infrastructure disruptions interrupt firms' activities, force them to operate at less than full production capacity, reduce their sales, and cause delays in the supply and delivery of goods. For instance, textile industries relying on electricity cannot produce due to power cuts, or likewise, a firm relying on water to cool a machine cannot manufacture products during a dry out.

(ii) Indirect impact: The indirect impacts of unreliable infrastructure are less immediate. They affect firms' investment decisions, sway what products can and cannot be produced, and manipulate the composition and innovativeness of an industry. For example, a firm is less likely to upgrade its machinery to more productive technology if power cuts happen frequently. In addition, due to interruption of power or logistics activities which make firms inability to provide on-demand goods and services, consequently firms become less competitive in the market. In the aggregate, these effects are visible in an economy's ability to generate wealth and in its global competitiveness.

(iii) Induced impact: firms tend to incur costs for handling unreliable infrastructure. To mitigate the impacts of power cuts, firms used to own a backup power generator. However, power generators require a high operating cost which excludes more productive investments. Firms that locate in an area of inaccessibility to transport system may increase inventory capacity or worse, must move to expensive location in proximity to transport system, fast internet service...

Hence, the subject has been drawn attention of many studies over time. Our paper builds on an extensive literature that estimates the economic effects of electricity, water facilities, transportation, and telecommunication. The main objective of this paper is accordingly to specifically focus on various measures used to estimate the effects between infrastructure quality and business activities of firms. By the end, we aim to answer two very fundamental questions:

(1) What are relevant metrics of infrastructure quality and firm performance to perform an impact analysis that could be drawn from recent empirical research?

(2) What are the key findings in the research work about the relationship between infrastructure quality and firm performance by infrastructure sectors?

To attain the research purpose, we searched for infrastructure impact on firms related literature from about 2005 to 2021 including keywords such as "infrastructure impact", "road network/transportation", "power outages", "ICT effect on firms" "developing economies", and others. From the research reports identified, we checked the dataset used in the literature and chose research based on firm-level database. As a result, 56 literatures met inclusion criteria and included findings from national studies from China, India, Nigeria, Senegal, Kenya..., and international regions such as Eastern European and Central Asia, Middle East and North Africa, South Asia,
Africa, and others. Figure 1 visualizes the distribution of reviewed literature based on investigated infrastructure sectors, namely transportation sector, electricity sector, ICT sector and multiple sectors. As we see, at firm-level data, electricity and transportation sectors are more attractive to researchers. Furthermore, we also classified by location of research scope since the availability of various data types also relies on scale of studied area.

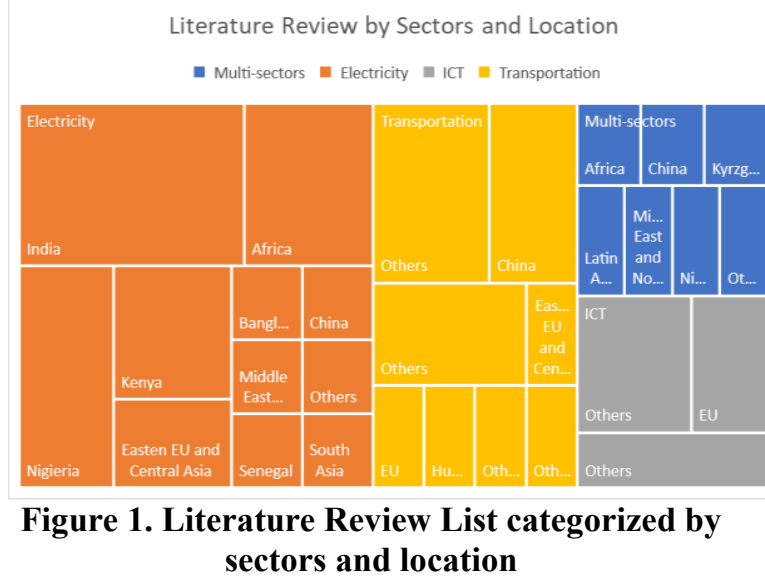

This paper proceeds as follows. Section 2 discusses the infrastructure quality metrics and firm performance metrics used in literature to date. Section 3 provides an extensive literature review, addressing measurement issues as well as data challenges in developing countries. Section 4 concludes.

\section{METRICS OF INFRASTRUCTURE QUALITY AND FIRM PERFORMANCE}

Metrics of infrastructure quality and firm performance are highly dependent on the type of data collected to achieve the research objectives. In studies on the topic of measuring the impact of infrastructure on business operations, it is classified into two types of data: (i) primary data that the author designed to survey the current situation of the local infrastructure system and (ii) secondary data provided by the local government or the statistical department of a country or an international organization such as the World Bank, European Bank or United Nations. It reveals the fact that the choice between primary or secondary data depends on the location in which the research is interested. At the country or regional level, the secondary dataset conducted by the World Bank (ES survey) or European Bank (BEEPS database) is broadly accepted, while at the city level, researchers prefer to conduct their own questionnaires. Therefore, metrics for each type of data source are varying accordingly.

\subsection{Metrics of infrastructure quality}

Infrastructure quality is commonly reckoned in terms of three main aspects, these are (i) accessibility (ii) reliability and (iii) ease of connection.

(i) Accessibility measures access to infrastructure services such as power/water supplied to firms or 
access to main roads at specific location. Accessibility depends on the functionality of the critical facilities chain of generation, transmission, and distribution. In the class of primary data, infrastructure accessibility metrics are mainly measured on nominal and ordinal Likert scales. The nominal scale or binary data type is applied to firms surveying whether there is access to public infrastructure at firm's location. Furthermore, accessibility measure can be converted to Likert scales when firm rate how difficulty to access the power water supply, internet service or access to highways, port from 1 to 5 level of inconvenience.

(ii) Reliability/quality is measured by the number of infrastructure service interruption per day as well as duration of service interruption. This distinction is important because firms can provide alternative source of electricity/water supply during interruption which tend to mitigate the loss level of infrastructure insecurity on the business. To investigate the quality/reliability of public infrastructure, in the class of primary data, interviewers asked firms to assess their public infrastructure experience at a 5-level Likert scale, from "Complete strongly disagree" to "Strongly agree". The question is designed to test firms' perceptions of infrastructure services such as "I do not get enough electricity supply for my business" or "I have no idea when the outages will stop". As a result, estimation methods for ordinal data were used. Various estimation techniques such as normality test, linearity test, Exploratory Factor Analysis EFA, Confirmatory Factor Analysis CFA and Structural Equation Model were employed in estimating the effects between infrastructure factors and business cost, business performance. In addition, Alpha Cronbach's, discriminant, and convergent validity estimate were generated to validate the measurement model.

In the class of secondary data, the metrics for infrastructure quality and firm performance are much more ample. The firm-level data used in tremendous studies come from Business Environment and Enterprise Performance Survey (BEEPS) or Enterprise Survey (ES survey) which were conducted by the European Bank for Reconstruction and Development and the World Bank. Based on this survey, infrastructure factors are carefully investigated at mainly three services, namely electricity, water supply and telecommunications. For each sector, the database measure two types of service quality: annual frequency and daily duration of service suspensions. For instance, the information on how many days a firm experienced power outages last year are available. This varies from zero to 365 days. The database also provides the information on how many hours a power outage lasted on average if it happened. This varies from zero to 24 hours. Since the raw data is collected in days, hours unit, they are transformed to input into the impact models as following:

- The total number of service suspension during the year is given by:

$$
n=\sum_{i=1}^{5}\left(n_{i} \times 365\right)
$$

Where, $n_{i}$ is the number of times of incidence of suspension daily on average of duration; $i=1,2,3,4,5$ which means that $1=$ duration from 0 to $0.5 \mathrm{hr}$; $2=$ duration from $0.5 \mathrm{hr}$ to $1 \mathrm{hr} ; 3=$ duration from $1 \mathrm{hr}$ to $2 \mathrm{hr}$; $4=$ duration from $2 \mathrm{hr}$ to $3 \mathrm{hr} ; 5=$ duration from 3 $\mathrm{hr}$ and above.

- The total time lost due to suspension

$$
t=\sum_{i=1}^{5}\left(n_{i}\left(\mathrm{~d}_{i}+y i\right) \times 365\right)
$$

where, $\gamma_{i}$ : restart time after a suspension of duration $i$; $d_{i}$ : duration of suspension.

Many research directly take the natural logarithm of these continuous variables to build into their model, whereas some research prefer to use infrastructure reliability indicators computed by Doing Business survey $^{1}$ namely GE indicator. GE indicator includes two indicators such as the system average interruption duration index (SAIDI) and the system average interruption frequency index (SAIFI) which are formulated as below:

$$
S A I D I=\frac{\sum \mathrm{N}_{i x}}{N_{t x}} \quad(3) \quad \text { SAIFI }=\frac{\sum\left(r_{i} \times \mathrm{N}_{i x}\right)}{N_{t x}}
$$

where, $N_{i x}=$ Total number of customers interrupted over year x; $N_{t x}=$ Total number of customers served over year x; $R_{i}=$ Average restoration time (in hours)

The GE indicator provides power outage data for each economy's largest business city and the second largest city in 11 economies. By formularization, it is easy to see that such indicators are appropriate to measure impact at macro level. Arlet (2017) employs SAIDI and SAIFI metrics to assess the impacts of public utilities such as electricity, and telecommunications using firm-level data for 190 countries in Eastern Europe and Central Asia.

(iii) Another metric could be used to quantify the infrastructure services is the ease of the connection process. ES survey provides data of duration for application for electricity/water connection, measured in days unit. At firm level research, this data is utilized directly into the models, whereas at country/regional level research, it is transformed into average connection time of all firms located in that specific country/region. The ease of connection process is also collected in primary data in which firm rates how convenient for firms to apply a water/power connection in term of time and cost together.

\subsection{Metrics of firm performance}

\footnotetext{
1 Doing Business survey presents the ease of doing business score and ease of doing business ranking across 190 economies-from Afghanistan to Zimbabwe - and over time. It provided methodologies to measure quantitative indicators on business regulations such as starting a business, dealing with construction permits, getting electricity, registering property, getting credit, protecting minority investors, paying taxes, trading across borders, enforcing contracts, and resolving insolvency.
} 
Measuring the performance of the firm is an important activity that underpins the strength of any business. The performance of firms is usually evaluated from different points of view. In literature survey, operational measures such as operating cost, profitability, productivity, and innovation are the most mentioned ones. These metrics are more frequently employed in the literature for manufacturing enterprise performance in accordance with concept of measuring the impact of infrastructure factors.

(i) Operating cost as firm performance metric

First and foremost, unreliable and inefficient infrastructure system impacts the firm outcome directly in terms of operating cost. Any disruption of infrastructure lead to negative effects on the continuity of production process and service delivery, diminishing aggregate productivity. To cope with these disruptions, firms need to invest excessively in an expensive backup system or technology and consequently increasing the operating cost. Therefore, to measure these adverse impacts, many research utilize operating costs to expose firm performance due to infrastructure disruptions. Operating cost could be performed in terms of losses associated with power/water outage as a percentage in total sales in a specific period, or capacity utilization upon on availability of the database. Most studies use cost function assuming that firm's costs are dependent on fixed cost which are affected by the quality of infrastructure services rather than variable costs of production. For instance, the cost incurring due to suspension of water or electricity can be counted on a fixed expense since the water suspensions may affect the quality of product or power outage may incur extra salaries for employees after electricity restoration. Imi (2011) regresses relationship between quality of infrastructure and the total operating cost, then compute the marginal impact of improved infrastructure quality on firms' costs. Rentscheler et al (2019) measure impact of power outage on self-reported sale losses. The World Bank's enterprise survey provides data of losses on total sales due to infrastructure suspensions which are anticipated by firm owners or managers.

In case that such self-reported losses data are not available, some studies use capacity utilization rate instead. Capacity utilization is a common metric used to calculate the rate at which the prospective levels of output are being met or used. The rate is displayed as a percentage and provides an insight into the total utilization of resources and how a firm is limited to its full production capacity because of frequent disruptions of electricity, water, or transport infrastructure. As a result, many research (Rentscheler et al 2019) analyze a model that simultaneously estimates the impact of water, electricity, and transport disruptions on a firm's utilization rate. When investigating the impact of specific sector such as electricity, James (2013) proposes formular to compute the capacity utilization based on electricity real consumption. Accordingly, capacity utilization refers to the intensity with which the resources of the firm are employed. It is captured by amount of electricity that a firm consumes in a month, when this is normalized by the number of hours that the firm is connected to the electricity grid:

$u_{i t}=\frac{C E_{i t}}{H_{i t}}$

Where $C E_{i t}$ is the electricity consumption of firm $i$ at month $t, H_{i t}$ is the number of hours on grids of firm $i$ at month $t$ which can be calculated by taking the total production hours minus the hours of outage. By this definition, electricity consumption can be proxied as a measure for utilization rate.

(ii) Productivity as firm performance metric

Impact of infrastructure can be captured via productivity as well. There are many different productivity measures. The choice between them depends on the purpose of productivity measurement and, in many cases, on the availability of data. Generally, productivity measures can be classified as single factor productivity measures (relating a measure of output to a single measure of input) and total factor productivity measures (TFP - relating a measure of output to a bundle of inputs). Under the mechanism that reliable and efficient infrastructure service would increase productivity, or highly productive firms may have access to more reliable and efficient public services, labor productivity is mostly used in model estimating the impact of infrastructure. The labor productivity can be defined at firm level as

Productivity $_{i, t}=\frac{Y_{i}}{L_{i}}$

Where $Y_{i}$ is total gross sales and $L_{i}$ is total employees. Studies which employ ES firm-level data, also use productivity of firm $i$ at time $t$ for availability of panel data or at aggregate level, or it could expand to productivity of firm $i$ in country $c$ at time $t$ (Arlet 2017) depending on research's scope.

Another common productivity measure is multifactor productivity or total factor productivity (TFP). The variables used to estimate firm-level TFP including total sales (revenues), raw materials cost and total employees.

Formally, TFP is calculated from Cobb-Douglas production function as

$T F P_{i}=\frac{V A_{i}}{L_{i}^{\alpha} K_{i}^{\beta}}$

Where $V A_{i}$ is real value added which is the real value of output adjusted for the real cost of all intermediate inputs; $L_{i}$ is labor input. Real value added is defined by subtracting the raw materials cost from total sales. According to (7), TFP is calculated by dividing output by the weighted geometric average of labor and capital input, with the weighting of $\alpha$ for labour and $\beta$ for 
capital. The labor and capital elasticities could be calibrated from Input - Output table ${ }^{2}$ at country level or by adapting semiparametric estimation approach proposed by Levinsohn and Petrin (2003) at firm level (Wan and Zhang 2017).

Another econometric approach is commonly applied to compute firm level TFP as the residual of the

$$
V A_{i t}=\mu_{\mathrm{i}}+\mu_{\mathrm{t}}+\alpha_{1} L_{i}+\alpha_{2} K_{i t-1}+\varepsilon_{\mathrm{it}}
$$

equation:

then,

$$
\widehat{T F P_{l t}}=\widehat{\varepsilon_{l t}}=V A_{i t}-\mu_{\mathrm{i}}-\mu_{\mathrm{t}}-\alpha_{1} L_{i}
$$

where $V A_{i t}$ is real sales minus raw materials cost; $K_{i t-I}$ is capital stock in previous term; $L_{i t}$ is employment; $\mu_{i}$ is a firm fixed effect to capture permanent differences across firms; $\mu_{t}$ is a time fixed effect to capture aggregate changes common to all firms.

Putting all metrics together, a range of regression models are constructed to evaluate the effects of infrastructure on firm operating cost/firm productivity. Firm operating cost and firm productivity is set up as dependent variable, whereas a range of infrastructure metrics (raw value or index value) are used as independent variables. Models is also controlled by firm specific variables such as firm size, capital intensity, export status or ownership dummy variables (Arlet 2017, Rentschler et al 2019). Further, many fixed effects caused by location, by industries or by years are included as well in an impact regression models (Wan and Zhang 2017). Basically, the regression is defined in form of cost function as:

$$
C_{i}=\beta_{0}+\beta_{\mathrm{Y}} Y_{i}+\beta_{\mathrm{L}} L_{i}+\beta_{\mathrm{K}} K_{i}+\beta_{\mathrm{Zk}}{ }^{\prime} Z_{k}+u_{\mathrm{i}}
$$

where $\mathrm{C}_{\mathrm{i}}$ denotes the total operating cost of firm $i, \mathrm{Y}_{\mathrm{i}}$ is output proxy and $\mathrm{L}_{\mathrm{i}}, \mathrm{K}_{\mathrm{i}}$ as input prices; $\mathrm{Z}_{\mathrm{k}}$ is a vector of $k$ th measure of infrastructure quality.

In the form of Cobb-Douglas typed production function is defined as:

$$
\begin{gathered}
\text { TFP } P_{i t}=\beta_{0}+\beta_{1} I N F R A S_{i t}+\delta^{\prime} X_{i t}+\mu_{\mathrm{k}}+\mu_{\mathrm{t}} \\
+u_{\mathrm{it}}
\end{gathered}
$$

where the subscripts $i$, $t$ index the firm and years respectively; TFP is the total factor productivity calculated from (9); INFRAS stands for the infrastructure quality (one or multi metrics as described (i); $\mathrm{X}$ is a vector of firm specific control variables and $\mu_{\mathrm{k}}$ is a industry fixed effect to capture permanent differences across firms in industries; $\mu_{\mathrm{t}}$ is a time fixed effect to capture aggregate changes common to all firms.

TFP is a common summary statistic for evaluating the performance of a firm or a industry. Generally,

\footnotetext{
2 The input-output (I-O) table records the flows of goods and services using the transaction values between industries. It shows for each industry what kinds of products are purchased with what amount as inputs to produce its output (the column), or to which industries/final Demand sectors the product is supplied for further use (the row).
}

most developed countries have data which are almost well fitted for obtaining measures of either labor productivity or TFP. By contrast, for developing countries, the variables required for TFP calculations are not readily available, or only in very small numbers. Distinction between labor productivity (as total gross sale per employee) and TFP (value-added per employee) gives researchers a slightly broader indicator of firm performance: for instance, a firm might be quite productive on the factory floor but suffer from very high transport costs, decreasing its TFP relative to labor productivity. One more advantage of utilizing TFP is that it allows to compare across sectors or industries which is common controlled in infrastructure impact analysis.

\section{A LITERATURE REVIEW OF INFRASTRUCTURE IMPACT EVIDENCE}

In this section, the paper aims to examine the range of recent research working on interested topics and summarize the key findings on research of evaluating impact of public infrastructure on firm performance. The review is analyzed in accordance with aspect to the availability of firm level data (aggregate or disaggregate data) and the sources of impacts (by which sectors: transportation, electricity/water or telecommunication).

As mentioned in Fay and Morrison (2007), data on the quality of public infrastructure service are difficult to measure and generally thin. Therefore, the availability of quality data effects the research scope in some way. One of the most advantage of firm level data provided by $\mathrm{WB}$ or $\mathrm{EB}$ is that such data allow to capture potential heterogeneity in public utilities service within a country (developed country versus developing country) or within an interregional area (urban area versus rural area). Figure 2 shows the distribution of percentages of firms experiencing with power outages around the world based on ES survey of World Bank.

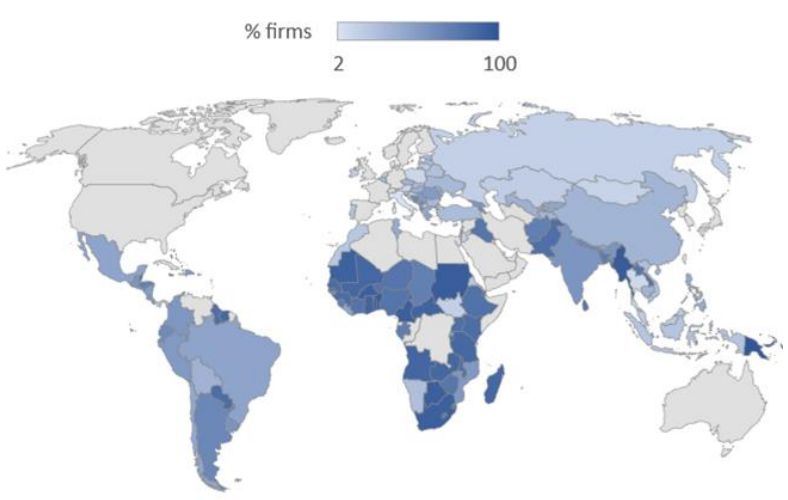

Figure 2: Percentage of firms experiencing frequent power outages by country.

(Source: World Bank 2019 ES survey data)

On the aggregate level, many research conduct a comparative analysis across countries to investigate effects of public infrastructure on business performance. 
Iimi (2011) focuses on the impacts of improving the quality of public utilities (electricity, water supply, and telecommunications), using firm-level data from 26 transition economies in Eastern Europe and Central Asia. The firm-level data used in this paper allow the study to take into consideration the fact that the quality levels of infrastructure services received by individual firms are different in different places in a country. The paper indicates that firms' costs are dependent on a productivity or fixed cost parameter, which is affected by the quality of public infrastructure services. Moyo (2013) conducts a study to examine the impact of the quality of power infrastructure on productivity of manufacturing firms in five Sub Saharan African countries. The paper measured power infrastructure quality using the number of hours per day without electricity and the percentage of output lost due to outages and found these indicators to be negative and significant determinants of productivity. Arlet (2017) tests the relationship between electricity sector characteristics, as measured by Doing Business, and firm performance in a cross-sectional sample of 80 economies and confirms that power outages are negatively associated with firm productivity. Similarly, impact of public utilities services has been revealed in many economies such as Middle East and North Africa (Antonio et al 2013), Central Asia (Azhgaliyeva et al 2021; Karymshakov \& Sulaimanova, B. 2019).

On a disaggregated level, many attempts to estimate the impact of poor infrastructure services on firms in a specific country or a specific region within a country are implemented. Africa is the region in which infrastructure condition is still extremely limited. Figure 3 shows the average percentage of firms stating "electricity" and "transportation" as major constraints by regions in the world. It can be revealed that Africa constitute the lowest public infrastructure quality in the world, consequently, the average firm's utilization rate in this region is the lower (the blue line).

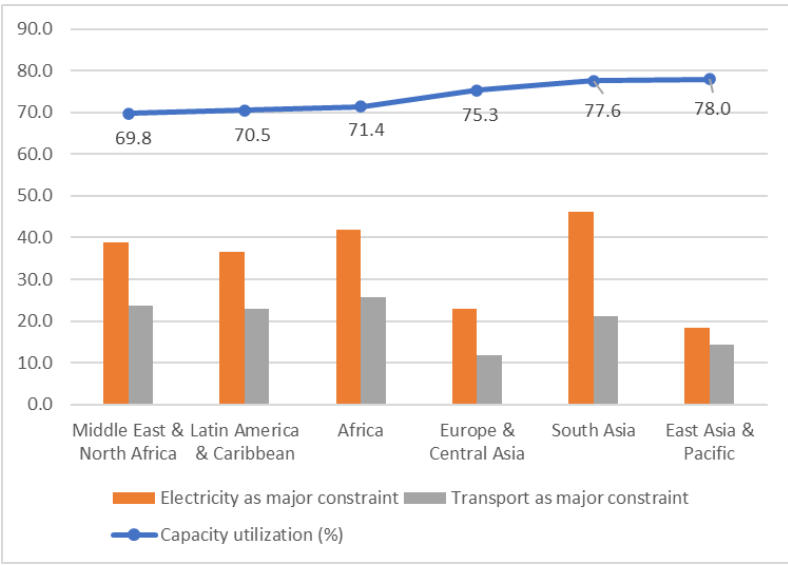

Figure 3: Percentage of firms indicating infrastructure as major constraint and firm's capacity utilization by region. (Source: author's summarization based on World Bank 2019 ES survey data)

Therefore, number of research carrying out an impact analysis in this area is abundant such as in Nigeria
(Obokoh and Goldman 2016; Akinyele et al 2016), Senegal (Lassana \& Abdoulaye 2013), South Africa (Boonzaaier et al 2015), Kenya (Mugo \& Kinyua 2019). Several recent papers focus specifically on Indian electricity supply: Ryan (2013) estimates the potential welfare gains from expanding transmission infrastructure, Cropper et al (2011) and Chan, Cropper, and Malik (2014) study the efficiency of Indian coal power plants, and Abeberese (2012) tests how changes in electricity prices affect manufacturing productivity. Hunt Allcott et al (2014) study how electricity shortages affect all Indian manufacturers, using an instrument based on hydroelectricity production and a hybrid Leontief/Cobb-Douglas production function model.

Most of above-mentioned studies tend to mix the indirect and direct effects as the total effect when estimating the impact of infrastructure. There are few studies attempting to distinguish between direct and indirect effects on firm of public infrastructure. Wan and Zhang (2017) conduct an empirical study to estimate the direct and indirect effects of infrastructure on Chinese firms' productivity and find out that road, telecommunication, and electrification directly increase firm productivity. Furthermore, study reveals that public utilities also exert a positive indirect effect on productivity through the agglomeration channel. Similarly, Abbas (2016) quantifies the various costs incurred due to power outages in Punjab by the small-scale manufacturing sector. The paper estimates separately direct costs like spoilage cost or value of output loss and indirect costs like inbuilt power generation costs (capital cost, fuel cost, operation and maintenance costs of generators).

In the sector-specific literature, number of research on evaluating impact of transportation on firms is dominant in comparison to power/water supply and telecommunication. Roads are normally found productive and instrumental in growth (Fan, Zhang, and Zhang 2002; Luo 2004; Shepherd et al 2006; Shirley et al 2004). The benefits from roads can outperform even the labor cost advantage (Boudier Bensebaa 2005). Good road infrastructure will help to lower distribution and inventory costs of businesses (Shirley and Winston 2004). Impact of transportation sector is investigated in many recent research including Banerjee, Duflo, and Qian (2012), Donaldson (2012), and Donaldson and Hornbeck (2013) on the effects of railroads in China, India, and the United States. A subset of this literature focuses on electricity supply. Hunt Allcott et al (2014) study how electricity shortages affect all manufacturers and indicate that firms without generators have much larger losses, and because of economies of scale in generator capacity, shortages more severely affect small firms.

In addition, telecommunications infrastructure has been found especially influential (Lio and Liu 2006). Information and communication technology (ICT) infrastructure plays an increasingly important role, in relatively small countries pursuing for export-led 
growth; it could contribute to shrinking geographic distance as well as improving labor productivity (Jalava and Pohjola 2007). The impact on operational performance has been studied mainly using productivity measures and cost reduction (Das et al, 2011). ICT increases productivity and operational efficiency in specific business processes, not only by reducing costs but also by impacting on intangible assets such as quality improvement in design processes or life-cycle enhancement in inventory management systems (Melville et al 2004).

Generally, the key findings based on infrastructure sectors (transport, electricity, water, or ICT) can be summarized as follows:

- The firm-level data used in each paper allows it to take into consideration the fact that the quality levels of infrastructure services received by individual firms are different in different places in a country.

- Most literatures indicate that poor roads/transport and electricity outages are major problems. Regarding to effects of electricity services, shorter but more frequent electricity outages seem to be less harmful for firms than longer but less frequent ones. However, frequent water interruptions may not be problematic. The evidence can be interpreted to mean that unlike electricity, repeated short interruptions of water supply could be accommodated if the services are restored quickly. The measured quality of telecommunications services seems to have little role to play in influencing firm costs. This is possibly because telecommunications services, particularly in the mobile segment, are largely reliable in the sample region (most of them are urban areas), except for rural and remote areas.

- The interaction effects between firm size and industries vary by countries and regions. However, most research reveals that electricity disruption are only associated to the productivity of small and medium scale firms but not large firms. Large firms can be successful in minimizing the detrimental effects of infrastructure disruption. This is relevant to the 'missing middle' puzzle which notes that developing countries have far less medium sized firms than their more developed counterparts. Among the reasons that have been proposed to explain the puzzle are transaction costs, regulation, poor institutionalized support for small and medium firms and bias against small firms in industrial policy. These proposed explanations do not consider aspects of the business environment, which are specific to developing countries, like frequent disruptions in electricity/water supply. Large firms in these environments can minimize the effects of these shocks and so small/medium sized firms may be more negatively impacted without the existence of any explicit bias.

- The interaction terms between the manufacturing dummy and infrastructure do not suggest that infrastructure is any more associated to the productivity of firms in manufacturing versus services. As policy implication, this suggests that reliability is important for all private sector actors and efforts to improve it need not be targeted to groups of firms.

\section{CONCLUSION}

The economic effects of public infrastructure quality on firms' activities have been analyzed in many studies and evolved over time. Remarkable evidence of the impact that infrastructure disruptions have can be found in the World Bank's Enterprise Survey. In this survey, firm owners and managers are asked to identify a business environment element from a comprehensive list that represents the major constraint experiencing by firms. According to the survey, firms in South Asia and Africa tremendously choose electricity as the major constraint that they face. In the Middle East \& North Africa, transport is quoted as "the major constraint" (Figure 2). Most reviewed studies rely on the World Bank Enterprise Surveys, which consist, in most countries, of a cross-sectional data set, though in a few cases panel data is available. Obviously, cross-sectional data restricts the analysis and the findings. In addition, the World Bank Enterprise Surveys, particularly in the earlier rounds, largely gather only perception-based data which further limits the econometric analysis and interpretation of results.

Infrastructure quality is a significant component of production process. As such, limited public services quality has the potential to directly or indirectly, affect the economic activities of firms. A common approach in the literature is to measure the output loss associated with infrastructure disruption. One of the analytical frameworks used is a production function in which effectively contributes directly to firms' output as a separate input, and indirectly as a determinant of the extent to which other direct inputs such as capital equipment is used. An alternative approach, a subjective method, is based on self-reported by which surveys ask firms to quantify the loss they incur due to power outages. This approach relies on the assumption that firms are well-positioned to provide a relatively accurate valuation of how much it cost them to replace more frequently or to repair damaged machinery or equipment, or to assess the lost output due to idled inputs. A simple approach to evaluate the costs of infrastructure disruption consists of just aggregating the cost amounts provided in the survey. However, many biases can afflict the outcome, since firms may tend to overestimate the induced costs, hence, over-emphasizing the constraint that public infrastructure may affect their business activity. Because of this shortcoming, capacity utilization rate and total factor productivity (TFP) are more relevant metrics in the class of infrastructure impact analysis, thus in pair with such dependent variables, infrastructure quality measured by length of $\mathrm{road} /$ highway, duration of electricity/water suspension, length of internet cables are employed into estimated 
models. Regarding the research question about key influences of various infrastructure sectors on business activities, it could be summarized as: (1) High-quality infrastructure services play a vital role for both firm's growth and its competitiveness; (2) Quality of road infrastructure is important to explain patterns of absolute advantage, explaining why firm in one region produce more efficiently than firm in others; (3) Quality of power supply and telecommunication infrastructure is important for explaining patterns of comparative advantage which introduces opportunity cost as a factor for analysis in choosing between different options for production diversification. In addition, many research find out that transportation is critical for low or developing countries where technology-intensive industries are dominant, while electricity is essential for high technology-intensive industries. Concerning the interaction effect between industries and firm size, empirical research emphasizes the significant effect of electricity on small-scale firms. These various approaches, coupled with the specificities of countries, diversification of industries under study, have translated into a wide range of estimates. Therefore, for any infrastructure investment, the necessity to conduct impact analysis at a specific region level under various industries control is highly recommended.

\section{ACKNOWLEDGMENT}

This research is funded by Hanoi University of Science and Technology (Grant number T2021-TT-011)

\section{REFERENCES}

[1] Abbas Malaika (2016). The Direct and Indirect Costs of Power Outages to Small Scale Manufacturing Industries of Punjab. MPRA Paper No. 83189, 08 Dec 2017

[2] Abeberese, Ama Baafra (2012). "Electricity Cost and Firm Performance: Evidence from India." Working Paper, Columbia University (November).

[3] Akinyele, S. T., Akinyele, F. E., \& Ajagunna, O. D. (2016). Infrastructural development as a predictor to small and medium enterprises performance in Nigeria. Kuwait Chapter of Arabian Journal of Business and Management Review, 6(3), 1-14

[4] Antonio Estache, Elena Ianchovichina, Robert Bacon, Ilhem Salamon. 2013. Infrastructure and Employment Creation in the Middle East and North Africa, The World Bank publication.

[5] Azhgaliyeva, Dina; Mishra, Ranjeeta; Yoshino, Naoyuki; Karymshakov, Kamalbek. 2021. Infrastructure and Firm Performance in CAREC Countries: Cross-Sectional Evidence at the Firm Level. (C) Asian Development Bank Institute. http://hdl.handle.net/11540/13709. License: CC BY 3.0 IGO.
[6] Banerjee, Abhijit, Esther Duflo, and Nancy Qian (2012). "On the Road: Access to Transportation Infrastructure and Economic Growth in China." Working Paper, Yale University (February).

[7] Benn Eifert, Alan Gelb, Vijaya Ramachandran (2008), The Cost of Doing Business in Africa: Evidence from Enterprise Survey Data, World Development, Volume 36, Issue 9, Pages 1531-1546, ISSN 0305-750X.

[8] Bonzaaier, Goliger, Makrelov and MacMillan (2015), The Tipping Point: The Impact Of Rising Electricity Tariffs At Firm And Sector, Economics Society of South Africa.

[9] Boudier-Bensebaa, Fabienne. 2005. "Agglomeration Economies and Location Choice: Foreign Direct Investment in Hungary." Economics of Transition 13, no. 4: 605-28.

[10] Chan, Hei Sing (Ron), Maureen Cropper, and Kabir Malik (2014). “Are Power Plants in India Less Efficient than Power Plants in the United States?", American Economic Review, Papers and Proceedings.

[11] Cropper, Maureen, Alexander Limonov, Kabir Malik, and Anoop Singh (2011). "Estimating the Impact of Restructuring on Electricity Generation Efficiency: The Case of the Indian Thermal Power Sector." NBER Working Paper No. 17383 (September).

[12] Das, S., Yaylacicegi, U. and Menon, N. (2011), "The effect of information technology investments in healthcare: A longitudinal study of its lag, duration, and economic value", IEEE transactions on engineering management, Vol, 58, No. 1, pp. 124-138

[13] Donaldson, D. and R. Hornbeck, R. (2013). "Railroads and American Economic Growth: A 'Market Access' Approach," NBER Working Paper 19213.

[14] Enterprise Surveys, 2015, The World Bank, http://www.enterprisesurveys.org

[15] Fan, Shenggen; Linxiu Zhang; and Xiaobo Zhang. 2002. Growth, Inequality, and Poverty in Rural China: The Role of Public Investments. Research Report 125. Washington, D.C.: International Food Policy Research Institute.

[16] Fay, Marianne, and Mary Morrison. 2007. Infrastructure in Latin America and the Caribbean: Recent Developments and Key Challenges. Washington, D.C.: World Bank.

[17] Fedderke, J. and Bogetic, Z. 2006. Infrastructure and Growth in South Africa: Direct and Indirect Productivity Impacts of Nineteen Infrastructure Measures. World Bank Policy Research Working Paper, Washington D.C.

[18] Fernald, John G. 1999. "Roads to Prosperity? Assessing the Link between Public Capital and 
Productivity." American Economic Review 89, no. 3: 619-38.

[19] Fernandes, Ana M. 2006. "Firm Productivity in Bangladesh Manufacturing Industries." Policy Research Working Paper no. 3988. Washington, D.C.: World Bank.

[20] Fisher-Vanden, K., Mansur, E. T., and Q. Wang. 2015. Electricity shortages and firm productivity: Evidence from China's industrial firms. Journal of Development Economics, 114, 172-188.

[21] Greene, William H. 1997. Econometric Analysis, 3rd ed., Upper Saddle River, N.J.: Prentice Hall.

[22] Holl, Adelheid. 2004. "Manufacturing Location and Impacts of Road Transport Infrastructure: Empirical Evidence from Spain." Regional Science and Urban Economics 34, no.3: 341-63.

[23] Hunt Allcott, Allan Collard-Wexler, and Stephen D. O'Connell 2014. How Do Electricity Shortages Affect Productivity? Evidence from India, NBER Working Paper No. 19977, March 2014.

[24] Iimi, A. (2011). Effects of improving infrastructure quality on business costs: Evidence from firm-level data in Eastern Europe and Central Asia. The Developing Economies, 49(2), 121-147.

[25] Ivan Ark, Bart, and Marcin Piatkowski. 2004. "Productivity, Innovation and ICT in Old and New Europe." International Economics and Economic Policy 1, no. 2-3: 215-46.

[26] Jacoby, Hanan G. 2000. "Access to Markets and the Benefits of Rural Roads." Economic Journal 110, no. 465: 713-37.

[27] Jalava, Jukka, and Matti Pohjola. 2007. "ICT as a Source of Output and Productivity Growth in Finland." Telecommunications Policy 31, no. 89: 463-72.

[28] Jean Arlet. 2017. Electricity Tariffs, Power Outages and Firm Performance: A Comparative Analysis, The World Bank Report, March - 2017.

[29] Karymshakov, K., and Sulaimanova, B. (2019). Measuring the Impact and Financing of Infrastructure in the Kyrgyz Republic. ADBI Working Paper 988. Tokyo: Asian Development Bank Institute. Available: https://www.adb.org/publications/measuring-impa ct-and-financinginfrastructure-kyrgyz-republic.

[30] Karymshakov, K., and Sulaimanova. B. (2020). The Impact of Infrastructure on Trade in Central Asia. ADBI Working Paper 1184. Tokyo: Asian Development Bank Institute.

[31] Khandker, S. R., Samad, H. A., Ali, R., and D.F. Barnes. (2014). Who Benefits Most from Rural Electrification? Evidence in India. The Energy Journal,35(2).

[32] Kinyua, A. N. (2014). Factors affecting the performance of Small and Medium Enterprises in the Jua kali sector in Nakuru Town, Kenya. IOSR Journal of Business and Management (IOSR-JBM) e-ISSN: 2278487X, p-ISSN: 2319-7668. 16(1). Ver. IV (Jan. 2014), 80-93.

[33] Kirkpatrick, C., Parker, D., and Y. Zhang. (2002). Electricity Sector Reform in Developing Countries: An Econometric Assessment of the Effects of Privatisation, Competition and Regulation. Centre on Regulation and Competition (CRC) Working paper no. 30593

[34] Kirubi, C., Jacobson, A., Kammen, D. M. and A. Mills. (2009). Community-Based Electric Micro-Grids Can Contribute to Rural Development: Evidence from Kenya. World Development, 73, pp. 1208-1221

[35] Klapper, L., Laeven, L., and R. Rajan. (2004). Business Environment and Firm Entry: Evidence from International Data. World Bank Policy Research Working Paper 3232. Washington, D.C.: World Bank.

[36] Lassana Cissokho and Abdoulaye Seck (2013). Electric Power Outages and the Productivity of Small and Medium Enterprises in Senegal, ICBE-RF Research Report N0. 77/13.

[37] Lee, K. S., Anas, A., \& Oh, G.-T. (1999). Costs of Infrastructure Deficiencies for Manufacturing in Nigerian, Indonesian and Thai Cities. Urban Studies, 36(12), 2135-2149.

[38] Limão, Nuno, and Anthony J. Venables. 2001. "Infrastructure, Geographical Disadvantage, Transport Costs, and Trade." World Bank Economic Review 15, no. 3: 451-79.

[39] Lio, Monchi, and Meng-Chun Liu. 2006. "ICT and Agricultural Productivity: Evidence from Cross-Country Data." Agricultural Economics 34, no. 3: 221-28.

[40] Luo, Xubei. 2004. "The Role of Infrastructure Investment Location in China's Western Development." Policy Research Working Paper no. 3345. Washington, D.C.: World Bank.

[41] Melville, N., Kraemer, K.L. and Gurbaxani, V. (2004), "Information technology and organizational performance: an integrative model of IT business value", MIS Quarterly, Vol. 28, No. 2, pp. 283-322.

[42] Michael Grimm, Renate Hartwig and Jann Layd (2013). Electricity Access and the Performance of Micro and Small Enterprises: Evidence from West Africa, European Journal of Development Research (2013) 25, 815-829. doi:10.1057/ejdr.2013.16;

[43] Mohammed Sani Abdullahi et al (2015), The Effect of Finance, Infrastructure and Training on the Performance of Small and Medium Scale Enterprises (SMEs) in Nigeria, International 
Journal of Business and Technopreneurship, Volume 5, No. 3, pp.421-452.

[44] Moyo (2013), Power infrastructure quality and manufacturing productivity in Africa: A firm level analysis, Energy Policy, Volume 61, 2013, Pages 1063-1070, ISSN 0301-4215.

[45] Mugo, A. N., Kahuthia, J. \& Kinyua, G. (2019). Effects of infrastructure on growth of small and medium enterprises in Kenya: A case of clothing and textile businesses in Nairobi Central Business District. International Academic Journal of Human Resource and Business Administration, 3(6), 133-149

[46] Obokoh, L.O., Goldman, G., (2016). Infrastructure deficiency and the performance of small and medium-sized enterprises in Nigeria's Liberalised Economy. Acta Commercii Independent Research Journal in the Management Sciences, 16(1), 1-10.

[47] Olugbenga, A. A. (2012). Policy support and performance of small and medium scale enterprises in South-West Nigeria. European Journal of Business and Management, 4(9), $10-18$.

[48] Piatkowski, Marcin. 2005. "The Aggregate Contribution of ICT to Output and Labor Productivity Growth in Transition Economies." In The Polish Miracle: Lessons for the Emerging Markets, ed. Grzegorz W. Kolodko. Aldershot: Ashgate.

[49] Rentscheler, Kornejew, Hallegatte, Braese, Obolensky 2019, Underutilized Potential: The Business Costs of Unreliable Infrastructure in Developing Countries, Policy Research Working Paper 8899, World Bank.

[50] Röller, Lars-Hendrik, and Leonard Waverman. 2001. "Telecommunications Infrastructure and Economic Development: A Simultaneous Approach." American Economic Review 91, no. 4: 909-23.

[51] Ryan, Nicholas (2013). "The Competitive Effects of Transmission Infrastructure in the Indian Electricity Market." Working Paper, MIT (September).

[52] Shepherd, Ben, and John Wilson. 2006. "Road Infrastructure in Europe and Central Asia: Does Network Quality Affect Trade?". Policy Research Working Paper no. 4104. Washington, D.C.: World Bank.

[53] Shirley, Chad, and Clifford Winston. 2004. "Firm Inventory Behavior and the Returns from Highway Infrastructure Investment." Journal of Urban Economics 55, no. 2: 398-415.

[54] van Ark, Bart, and Marcin Piatkowski. 2004. "Productivity, Innovation and ICT in Old and
New Europe." International Economics and Economic Policy 1, no. 2-3: 215-46.

[55] Wan, G. and Y. Zhang (2017), The Direct and Indirect Effects of Infrastructure on Firm Productivity: Evidence from Manufacturing in the People's Republic of China, ADBI Working Paper 714, Tokyo: Asian Development Bank Institute.

[56] Weninger, Quinn. 2003. "Estimating Multiproduct Costs When Some Outputs Are Not Produced.” Empirical Economics 28, no. 4: 75365. 